BMJ

Open

Gastroenterology

\section{Can topical epinephrine application to the papilla prevent pancreatitis after endoscopic retrograde cholangiopancreatography? Results from a double blind, multicentre, placebo controlled, randomised clinical trial}

To cite: Romano-Munive AF, García-Correa JJ, GarcíaContreras LF, et al. Can topical epinephrine application to the papilla prevent pancreatitis after endoscopic retrograde cholangiopancreatography? Results from a double blind, multicentre, placebo controlled, randomised clinical trial. BMJ Open Gastro 2021;8:e000562. doi:10.1136/ bmjgast-2020-000562

Received 2 November 2020 Revised 11 January 2021 Accepted 13 January 2021

Check for updates

(c) Author(s) (or their employer(s)) 2021. Re-use permitted under CC BY-NC. No commercial re-use. See rights and permissions. Published by BMJ.

${ }^{1}$ Instituto Nacional de Ciencias Medicas y Nutricion Salvador Zubiran, Tlalpan, Mexico ${ }^{2}$ Hospital Bernardette, Guadalajara, Mexico

${ }^{3}$ Medica Sur SA, Tlalpan, Mexico

Correspondence to Dr Felix Tellez-Avila; felixtelleza@gmail.com

\section{ABSTRACT}

Background and study aims Post-endoscopic retrograde cholangiopancreatography (ERCP) pancreatitis (PEP) is a complication associated with important morbidity, occasional mortality and high costs. Preventive strategies are suboptimal as PEP continues to affect $4 \%$ to $9 \%$ of patients. Spraying epinephrine on the papilla may decrease oedema and prevent PEP. This study aimed to compare rectal indomethacin plus epinephrine (EI) versus rectal indomethacin plus sterile water (WI) for the prevention of PEP.

Patients and methods This multicentre randomised controlled trial included patients aged $>18$ years with an indication for ERCP and naive major papilla. All patients received $100 \mathrm{mg}$ of rectal indomethacin and $10 \mathrm{~mL}$ of sterile water or a 1:10000 epinephrine dilution. Patients were asked about PEP symptoms via telephone 24 hours and 7 days after the procedure. The trial was stopped half way through after a new publication reported an increased incidence of PEP among patients receiving epinephrine. Results Of the 3602 patients deemed eligible, 3054 were excluded after screening. The remaining 548 patients were randomised to El group $(n=275)$ or WI group $(n=273)$.

The El and WI groups had similar baseline characteristics. Patients in the El group had a similar incidence of PEP to those in the WI group (3.6\% (10/275) vs $5.12 \%(14 / 273)$, $\mathrm{p}=0.41)$. Pancreatic duct guidewire insertion was identified as a risk factor for PEP (OR 4.38, 95\% Cl (1.44 to 13.29), $p=0.009$ ).

Conclusion Spraying epinephrine on the papilla was no more effective than rectal indomethacin alone for the prevention of PEP.

Trial registration number This study was registered with ClinicalTrials.gov (NCT02959112).

\section{Summary box}

What is already known about this subject?

- Post-endosretrograde cholangiopancreatography (ERCP) pancreatitis (PEP) is a complication associated with important morbidity, occasional mortality and high costs. Preventive strategies are suboptimal. The results of a network meta-analysis suggested that the most efficacious agent to prevent PEP is topical epinephrine. However, whether the combination of rectal indomethacin and sprayed epinephrine has added benefit remains controversial.

What are new findings?

- Our results shown that spraying epinephrine on the papilla was no more effective than rectal indomethacin alone for the prevention of PEP.

How might it impact on clinical practice in the foreseeable future?

- More studies are needed to find a combination of drugs which can decrease the incidence of PEP.

\section{INTRODUCTION}

Endoscopic retrograde cholangiopancreatography (ERCP) is a routinely performed endoscopic procedure with multiple therapeutic applications, but it is not devoid of potential complications. The overall complication rate for ERCP is typically reported as $5 \%$ to $10 \%$. Post-ERCP pancreatitis (PEP) is the most common and feared complication, 
with a frequency and mortality of $3 \%$ to $9 \%$ and $3 \%$, respectively. ${ }^{12}$ Risk factors for the development of PEP include those related to the patient and those associated with the procedure. Patient-related risk factors include female sex, previous pancreatitis, previous PEP, sphincter of Oddi dysfunction (SOD), jaundice, first ERCP and intraductal papillary mucinous neoplasm. ${ }^{34}$ Procedurerelated factors include difficult cannulation, endoscopic sphincterotomy, precut sphincterotomy and injection into the main pancreatic duct (PD). ${ }^{3-5}$

Multiple strategies have been evaluated to reduce the risk of PEP, including aggressive fluid resuscitation, PD stenting, use of gabexate, ulinastatin, statins, secretin, antibiotics, rectal indomethacin and epinephrine sprayed on the papilla. The use of rectal indomethacin is supported by evidence, ${ }^{6-11}$ and is currently recommended by the European Society of Gastrointestinal Endoscopy and the American Society for Gastrointestinal Endoscopy. ${ }^{12} 13$ Regarding the use of epinephrine, one trial showed that epinephrine sprayed on the major papilla can reduce the risk of PEP, ${ }^{14}$ and a network meta-analysis suggested that the most efficacious agent to prevent PEP is topical epinephrine. ${ }^{8}$ It remains unclear whether the combination of rectal indomethacin and sprayed epinephrine has an added benefit, with a preliminary study showing a potential benefit over indomethacin alone,${ }^{15}$ while a multicentre double-blind randomised trial reported no benefit in high-risk patients. ${ }^{16}$ Of particular concern, a recent multicentre randomised controlled trial was stopped early after an interim analysis concluded that the combination may actually be detrimental. ${ }^{17}$ Therefore, the aim of this study was to compare the efficacy and safety of rectal indomethacin plus epinephrine sprayed on the papilla (EI) versus rectal indomethacin and sterile water (WI) for the prevention of PEP, and to determine the risk factors associated with this complication.

\section{PATIENTS AND METHODS}

\section{Study design}

This multicentre randomised placebo-controlled trial was conducted in two hospitals. All patients provided written informed consent. This study received no commercial support.

\section{Patients}

We included patients aged 18 years or older with naive papilla and indication for ERCP. We excluded those patients with an allergy to indomethacin or epinephrine, pancreatic head cancer, chronic calcifying pancreatitis, renal insufficiency (serum creatinine $>1.4 \mathrm{mg} / \mathrm{dL}$ ), endotracheal intubation due to an indication other than ERCP, bilio-digestive bypass, pregnant patients and those unwilling to provide consent. Elimination criteria were the injection of epinephrine into the papilla to control bleeding and prophylactic placement of a pancreatic stent. Enrolment began in May 2016 and ended in June 2019. Recruitment was stopped early at 50\% enrolment because during the enrolment of our patients, one published study had found no difference in the incidence of PEP with epinephrine irrigated in the papilla, ${ }^{16}$ and a different one even reported a higher incidence of this complication. ${ }^{17}$ We included patients with high and average risk for PEP.

\section{Randomisation and masking}

The study coordinator performed the block randomisation, enrolled participants, assigned participants to interventions and collected data during procedure. Participants were allocated into groups by block randomisation using computed-generated numbers, in which 24 blocks were created with 40 patients each. The two groups were EI versus WI. Patients, endoscopists, nurses and assistants who participated in the procedure were kept blinded to the group allocation. Investigators who participated in the evaluation of post-ERCP complications were also blinded to group allocation to ensure blinding.

\section{Endoscopic retrograde cholangiopancreatography and treatment regimens}

ERCP procedures were performed with a videoduodenoscope (TJF-180F; Olympus, Tokyo, Japan), using iobitridol $300 \mathrm{mg} / \mathrm{mL}$ (Xenetix 300) as the contrast medium during the cholangiography. Patients were administered supplementary oxygen $(3-5 \mathrm{~L} / \mathrm{min})$ via a nasal cannula or a nasal mask, and their vitals were monitored during the procedure. All patients received local anaesthesia with a lidocaine spray. Systemic analgesia and sedation with propofol, fentanyl and midazolam were administered by a certified anaesthesiologist. Based on comorbidities and respiratory and haemodynamic status, some patients were intubated before the procedure. All ERCPs were performed by one of six staff physicians, all of them with at least 5 years of experience with $>200$ ERCPs per year.

All patients were given a dose of rectal indomethacin $(100 \mathrm{mg})$ at the beginning of the ERCP. Depending on the experimental group, either $10 \mathrm{~mL}$ of sterile water or $10 \mathrm{~mL}$ of a $1: 10000$ epinephrine dilution $(0.1 \mathrm{mg} / \mathrm{mL})$ was sprayed on the ampulla through a biliary balloon or a sphincterotome, avoiding any direct contact with the papilla during irrigation at the end of the procedure.

\section{Outcomes, assessments and follow-up}

The primary outcome of the study was to determine the incidence of PEP, and the secondary outcome was to identify the risk factors associated with the development of PEP.

Before the ERCP, relevant clinical information was collected, including age, gender, history of cholecystectomy, cholangitis or pancreatitis, diagnosis of SOD, intraductal papillary mucinous neoplasm, indication for ERCP and the presence of active cholangitis. Body mass index, triglyceride and bilirubin levels were recovered from each patient's chart. During the procedure, 


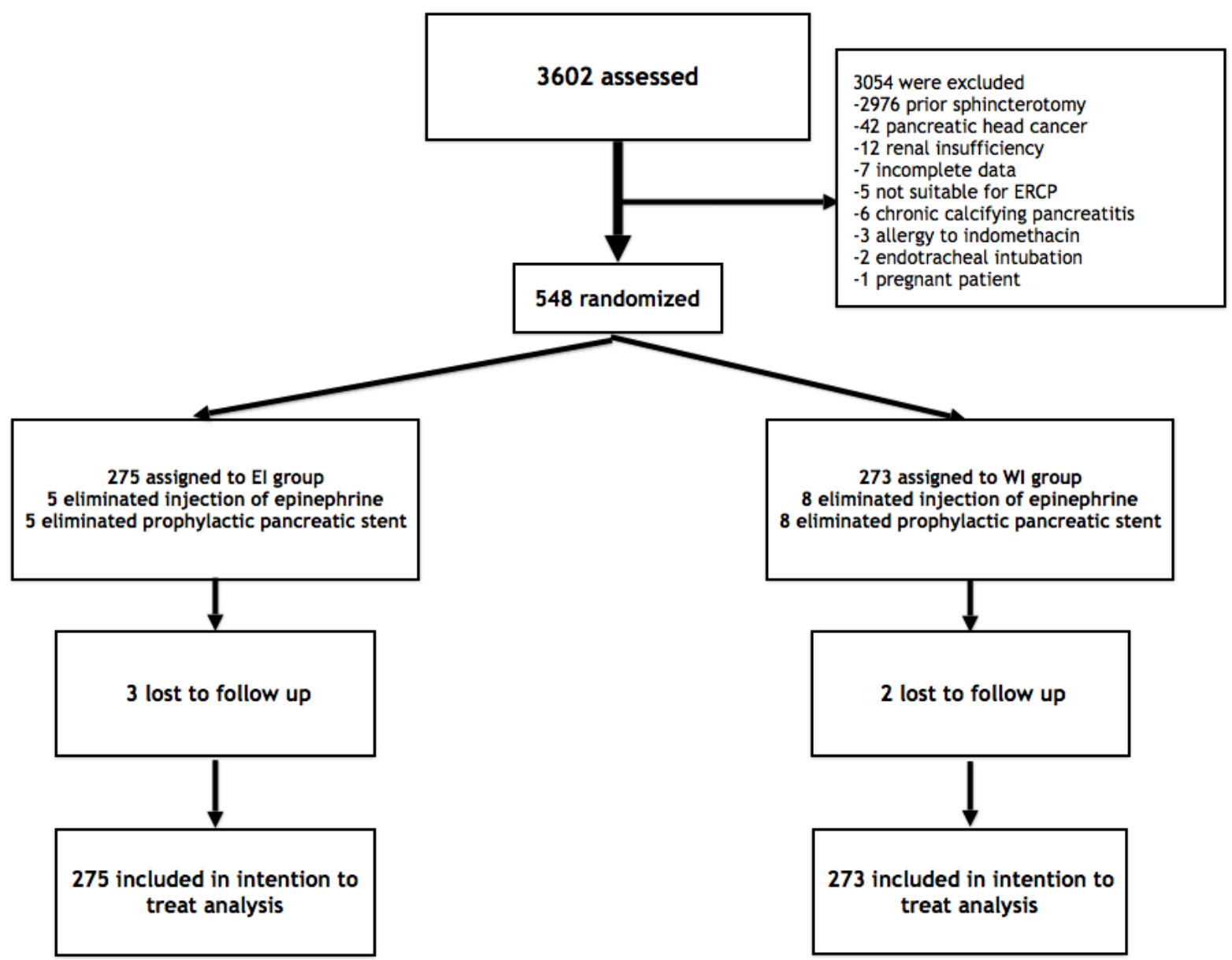

Figure 1 Flowchart of patients included in the study. El, rectal indomethacin plus epinephrine; ERCP, endoscopic retrograde cholangiopancreatography; WI, rectal indomethacin plus sterile water.

we recorded the common bile duct diameter, number of cannulation attempts, total volume of contrast media used, PD guidewire insertion, contrast injection of the $\mathrm{PD}$, number of injections of the PD and the presence of choledocholithiasis or periampullary diverticulum. We also documented if any of the following procedures were performed: biliary and/or pancreatic sphincterotomy, precut sphincterotomy, balloon dilatation of the sphincter of Oddi, ampullectomy, brushing of the PD or placement of a naso-biliary catheter. The total length of the procedure was documented in minutes, comprising the time from introduction to withdrawal of the duodenoscope. Difficult cannulation was defined as being unable to cannulate after $5 \mathrm{~min}$.

Patients were considered high risk for PEP if they met at least one major criteria (clinical suspicion of SOD, a history of PEP, pancreatic sphincterotomy, precut sphincterotomy, $\geq 8$ cannulation attempts, pneumatic dilatation of an intact biliary sphincter or ampullectomy) or two or more of the minor criteria (women younger than 50 years, a history of recurrent pancreatitis $\geq 2$ times, $\geq 3$ injections of contrast into the PD with $\geq 1$ injection to the tail of the pancreas, opacification of pancreatic acini or brush cytology performed on the PD).

After the procedure, patients were monitored in the recovery room for 2 hours and then discharged. Symptoms of acute pancreatitis or any other complication were interrogated at baseline while in the recovery room, and then by telephone 24 hours and 7 days after the procedure. Serum levels of pancreatic enzymes were determined only if the patient developed abdominal pain after ERCP. In those patients whose enzyme levels were normal despite a high suspicion of pancreatitis, a contrastenhanced CT scan of the abdomen was performed to rule out the diagnosis. Patients with PEP or other complication associated with ERCP (eg, bleeding, cholangitis, perforation) received standard-of-care management for these complications. The end of follow-up was at hospital discharge in patients who developed PEP or any other complication associated with ERCP, or after 7 days in patients who had an uncomplicated course.

PEP was defined according to the following criteria: (1) new onset of upper abdominal pain; (2) elevation in serum amylase or lipase levels of at least three times 
Table 1 Distribution of baseline characteristics of included patients by group

\begin{tabular}{|c|c|c|c|}
\hline & EI $(n=275)$ & WI $(n=273)$ & P value \\
\hline Age, years $($ mean $\pm S D)$ & $50.3 \pm 21.4$ & $51.8 \pm 20.3$ & 0.409 \\
\hline Female, $n(\%)$ & $188(68.3)$ & $192(70.3)$ & 0.617 \\
\hline Prior history of cholecystectomy, $n(\%)$ & $99(36)$ & $101(36.9)$ & 0.808 \\
\hline Current cholangitis, $n(\%)$ & $41(14.9)$ & $27(9.8)$ & 0.074 \\
\hline History of cholangitis, $n(\%)$ & $11(4)$ & $12(4.3)$ & 0.817 \\
\hline Current pancreatitis, $n(\%)$ & $1(0.3)$ & $4(1.4)$ & 0.175 \\
\hline History of pancreatitis, $n(\%)$ & $23(8.3)$ & $27(9.8)$ & 0.534 \\
\hline Diabetes mellitus, $n(\%)$ & $53(19.2)$ & $44(16.1)$ & 0.333 \\
\hline Total bilirubin, $m g / d L(m e a n \pm S D)$ & $5.1 \pm 5.1$ & $4.9 \pm 5.5$ & 0.645 \\
\hline Direct bilirubin, $m g / d L(m e a n \pm S D)$ & $3.8 \pm 4.1$ & $3.6 \pm 4.1$ & 0.460 \\
\hline Body mass index, $\mathrm{kg} / \mathrm{m}^{2}($ mean $\pm S D)$ & $24.6 \pm 9.2$ & $25 \pm 7.8$ & 0.589 \\
\hline Triglycerides, $m g / d L(m e a n \pm S D)$ & $162.4 \pm 85.6$ & $158.9 \pm 51.3$ & 0.798 \\
\hline \multicolumn{4}{|l|}{ Indications } \\
\hline Choledocholithiasis, $n(\%)$ & $208(75.6)$ & $202(73.9)$ & 0.657 \\
\hline Bile leak, $n(\%)$ & $21(7.6)$ & $19(6.9)$ & 0.760 \\
\hline Malignant biliary stricture, $n(\%)$ & $8(2.9)$ & $9(3.2)$ & 0.793 \\
\hline Benign or undetermined biliary stricture, $n(\%)$ & $7(2.5)$ & $16(5.8)$ & 0.052 \\
\hline Benign pancreatic diseases, $n(\%)$ & $6(2.1)$ & $7(2.5)$ & 0.768 \\
\hline Suspected SOD, $n(\%)$ & $1(0.3)$ & 0 & - \\
\hline Other, $n(\%)$ & $24(8.7)$ & $21(7.6)$ & 0.659 \\
\hline
\end{tabular}

Student's t-test and $\chi^{2}$ test were used.

El, epinephrine and rectal indomethacin; SOD, sphincter of Oddi dysfunction; WI, sterile water and rectal indomethacin.

the upper limit of the normal range at 24 hours after the procedure; and (3) hospitalisation or prolonged hospitalisation for at least 2 days. The severity of PEP was based on Cotton's criteria: (1) mild pancreatitis, if cases required fewer than 3 days of hospital admission; (2) moderate pancreatitis, if patients required from 4 to 10 days of admission; and (3) severe pancreatitis, if patients required more than 10 days of hospitalisation and/or it was complicated by the development of pancreatic necrosis or a pseudocyst.

After the publication of Luo et $a l^{17}$ who reported an increased incidence of PEP in patients receiving epinephrine and the publication of Kamal $e t a l^{16}$ who did not find differences between high risk groups, we decide to stop the trial in conjunction with The Committee of Investigation and The Committee of Ethics in Investigation of our hospital.

\section{Statistical analysis}

We used the formula for two proportions of two independent groups and estimated that 948 patients (474 in each arm) would be needed to detect a difference of $5 \%$ to $10 \%$ in the risk of PEP with a power of $80 \%$ and a two-tailed alpha of $5 \%$. Numerical variables are presented as the mean and $\mathrm{SD}$, and categorical variables as the absolute and relative frequencies, excluding observations from the denominator when missing. The Student's t-test and $\chi^{2}$ test were used to compare continuous and categorical variables between groups, respectively. Variables with $\mathrm{p}<0.2$ probability of having an association with PEP in the univariable analysis were included in the multivariable analysis, we use a stepwise backward approach. Logistic regression was used, with a $\mathrm{p}$ value of $\leq 0.05$ considered statistically significant. All results are from intention-totreat analysis. Data analysis was performed with SPSS Statistics 24.0 (Chicago, Illinois, USA).

\section{RESULTS}

During the study period, 3602 patients were deemed eligible, but 3054 were excluded after screening (2976 did not meet the inclusion criteria, 78 met the exclusion criteria; figure 1). The remaining 548 patients were randomly assigned to the EI group $(n=275)$ or the WI group $(n=273)$. The EI and WI groups had similar baseline characteristics (table 1 ).

The overall cannulation success rate for patients was 98.5\%. The ERCP procedure-related parameters and risk factors for PEP in the EI and WI groups were comparable, except for trainee involvement, trainees were involved in $95.8 \%$ of the procedures, $258(93.8 \%)$ in the EI group and $267(97.8 \%)$ in the WI group $(\mathrm{p}=0.020)$ (table 2$)$. A total of $325(59.3 \%)$ patients were considered at high risk for PEP, $154(56 \%)$ in the EI group and $171(62.6 \%)$ in the WI group $(\mathrm{p}=0.125)$. The two most common risk 
Table 2 Distribution of endoscopic retrograde cholangiopancreatography (ERCP) procedure-related parameters and risk factors for post-ERCP pancreatitis by group.

\begin{tabular}{|c|c|c|c|}
\hline & EI $(n=275)$ & WI $(n=273)$ & $P$ value \\
\hline Choledocholithiasis as an indication, $n(\%)$ & $208(75.6)$ & $202(73.9)$ & 0.657 \\
\hline Difficult cannulation ( $>5 \mathrm{~min})$ & $82(29.8)$ & 91 (33.3) & 0.376 \\
\hline Cannulation success rate, $n(\%)$ & $271(98.5)$ & $269(98.5)$ & 0.991 \\
\hline Trainee involvement, $n(\%)$ & $258(93.8)$ & $267(97.8)$ & 0.020 \\
\hline Number of cannulation attempts by trainee, $($ mean $\pm S D)$ & $2.6 \pm 4.1$ & $2.2 \pm 2.9$ & 0.328 \\
\hline Time of cannulation attempts by trainee, $\min (m e a n \pm S D)$ & $2.8 \pm 3.5$ & $2.9 \pm 4.7$ & 0.631 \\
\hline Number of cannulation attempts by professor, (mean $\pm S D)$ & $1.5 \pm 3.1$ & $1.5 \pm 2.3$ & 0.904 \\
\hline Time of cannulation attempts by professor, $\min ($ mean $\pm S D)$ & $2.2 \pm 4.4$ & $2.0 \pm 3.5$ & 0.574 \\
\hline Common bile duct diameter, $m m(m e a n \pm S D)$ & $9.1 \pm 7.4$ & $8.9 \pm 6.7$ & 0.668 \\
\hline Biliary sphincterotomy, $n(\%)$ & $224(81.4)$ & $206(75.4)$ & 0.087 \\
\hline Pancreatic sphincterotomy, $n(\%)$ & $9(3.2)$ & $13(4.7)$ & 0.374 \\
\hline Precut sphincterotomy, $n(\%)$ & $92(33.4)$ & $105(38.4)$ & 0.221 \\
\hline Pancreatic duct guidewire insertion, $n(\%)$ & $58(21)$ & $71(26)$ & 0.174 \\
\hline Pancreatography, $n$ (\%) & $13(4.7)$ & $16(5.8)$ & 0.553 \\
\hline Periampullary diverticulum, $n(\%)$ & $24(8.7)$ & $24(8.7)$ & 0.978 \\
\hline Choledocolithiasis, $n(\%)$ & $164(59.6)$ & $160(58.6)$ & 0.806 \\
\hline Balloon dilatation of the sphincter of Oddi, $n(\%)$ & $38(13.8)$ & 49 (17.9) & 0.185 \\
\hline Ampullectomy, $n(\%)$ & $2(0.7)$ & $6(2.1)$ & 0.280 \\
\hline Brushing of the pancreatic duct, $n(\%)$ & $1(0.3)$ & $1(0.3)$ & 0.481 \\
\hline Placement of a nasobiliary catheter, $n(\%)$ & $1(0.3)$ & 0 & - \\
\hline Volume of contrast media, $m L$ (mean $\pm S D$ ) & $20.8 \pm 13.5$ & $20.4 \pm 12.4$ & 0.697 \\
\hline Total length of the procedure, $\min (\operatorname{mean} \pm S D)$ & $26.7 \pm 20.3$ & $26.9 \pm 20.7$ & 0.916 \\
\hline
\end{tabular}

Student's t-test and $\chi^{2}$ test were used.

$\mathrm{El}$, epinephrine and rectal indomethacin; WI, sterile water and rectal indomethacin.

factors were precut sphincterotomy (197 patients, 35.9\%) and difficult cannulation (173 patients, $31.6 \%$ ).

PD guidewire manipulation occurred in $21 \%$ of the EI group and $26 \%$ of the WI group and pancreatography in $4.7 \%$ and $5.8 \%$, respectively. It was intentional in 13 patients because of pancreatic diseases, 129 patients had PD guidewire insertion, 59 of them one time, 35 two times, 15 three times and 20 four or more times. A double wire technique to achieve cannulation was done in 10 patients. PD therapeutic stents were placed in 13 patients and prophylactic stents were placed in also 13 patients, in the remaining cases a PD stent was not placed because loss of access to the PD during procedure or endoscopist decision.

There were no significant differences between the groups for complications and their severity (table 3 ). The overall incidence of PEP was $4.3 \%$. Patients in the EI group had a similar incidence of PEP to those in the WI group $(3.6 \%(10 / 275)$ vs $5.1 \%(14 / 273), \mathrm{p}=0.414)$. According to Cotton's criteria, mild, moderate and severe PEP were comparable between the two groups. Severe PEP was only found in one patient in the EI group. The overall mortality was $1.4 \%$, with five deaths due to a malignant tumour.
For high-risk patients, PEP was found in 8 of 154 patients $(5.1 \%)$ in the EI group and in 12 of 171 patients $(7.0 \%)$ in the WI group, $\mathrm{p}=0.520$. There was also no significant between group differences in the incidence of PEP in average-risk patients, PEP was found in 2 of 121 patients (1.6\%) in the EI group and in 2 of 102 patients $(1.9 \%)$ in the WI group, $\mathrm{p}=0.865$.

The univariable analysis revealed that prior cholecystectomy, history of pancreatitis, difficult cannulation, volume of contrast media, pancreatic sphincterotomy, PD guidewire insertion, pancreatography and the number and time of cannulation attempts by the professor were associated with PEP. Multivariable analysis showed that PD guidewire insertion (OR 4.38, 95\% CI (1.44 to 13.29), $\mathrm{p}=0.009$ ) and prior cholecystectomy (OR 2.52, 95\% CI (1.07 to 5.94), $\mathrm{p}=0.034$ ) were independent risk factors for PEP (table 4).

\section{DISCUSSION}

According to our results, there was no significant difference in the incidence of PEP between the EI and WI groups or between high-risk and average-risk patients. PEP is currently the most frequent and feared complication related to ERCP. The current standard of care to prevent this complication is 
Table 3 Complications observed in the included patients by group

\begin{tabular}{llll}
\hline & El (n= 275) & WI $\mathbf{( n = 2 7 3 )}$ & P value \\
\hline Total complications & 40 & 41 & 0.876 \\
\hline Pancreatitis & 10 & 14 & 0.393 \\
\hline Mild & 8 & 9 & 0.793 \\
\hline Moderate & 1 & 5 & 0.214 \\
\hline Severe & 1 & 0 & - \\
\hline Abdominal pain with normal lipase & 9 & 5 & 0.285 \\
\hline Bleeding & 9 & 3 & 0.147 \\
\hline Mild & 5 & 3 & 0.729 \\
\hline Moderate & 3 & 0 & - \\
\hline Severe & 1 & 0 & - \\
\hline Cholangitis & 5 & 10 & 0.185 \\
\hline Mild & 2 & 1 & 0.994 \\
\hline Moderate & 2 & 8 & 0.107 \\
\hline Severe & 1 & 1 & 0.481 \\
\hline Cholecystitis & 1 & 3 & 0.61 \\
\hline Fever & 4 & 0 & - \\
\hline Death related to ERCP & 1 & 2 & 0.994 \\
\hline Death related to malignant tumour & 1 & 4 & 0.364 \\
\hline Pancreatitis by group of risk & & & 0.52 \\
\hline Pancreatitis in high risk patients, $\mathrm{n}$ (\%) & & $12 / 171(7.0)$ & 0.865 \\
\hline Pancreatitis in average risk patients $\mathrm{n}(\%)$ & $8 / 154(5.1)$ & $2 / 102(1.9)$ & \\
\hline
\end{tabular}

$\chi^{2}$ test was used.

EI, epinephrine and rectal indomethacin; ERCP, endoscopic retrograde cholangiopancreatography; WI, sterile water and rectal indomethacin.

the use of rectal indomethacin. Other options have also been studied, including pancreatic stent, vigorous hydration and epinephrine sprayed on the major papilla.
In the past, two studies were conducted with sprayed epinephrine on the papilla for prevention of PEP, the first was conducted by Matsushita et al in 2009, they

Table 4 Univariable and multivariable analysis of risk factors for post-endoscopic retrograde cholangiopancreatography pancreatitis in the included patients, logistic regression analysis

\begin{tabular}{|c|c|c|c|c|c|}
\hline Univariable analysis & B & SE & Wald $\chi^{2}$ & OR $(95 \% \mathrm{Cl})$ & $P$ value \\
\hline Female & -1.169 & 0.624 & 3.503 & $0.31(0.91$ to 1.05$)$ & 0.061 \\
\hline Prior cholecystectomy & 0.934 & 0.424 & 4.850 & 2.54 (1.10 to 5.84$)$ & 0.028 \\
\hline Difficult cannulation & 1.167 & 0.425 & 7.553 & 3.12 (1.39 to 7.39$)$ & 0.006 \\
\hline Volume of contrast media & -0.060 & 0.021 & 8.021 & 0.94 (0.90 to 0.98$)$ & 0.005 \\
\hline Pancreatic sphincterotomy & 2.359 & 0.535 & 19.415 & 10.58 (3.70 to 30.22$)$ & $<0.001$ \\
\hline Pancreatic duct guidewire insertion & 2.190 & 0.462 & 22.510 & 8.93 (3.61 to 22.07 ) & $<0.001$ \\
\hline Pancreatography & 2.240 & 0.499 & 20.145 & 9.39 (3.53 to 24.99$)$ & $<0.001$ \\
\hline Number of cannulation attempts by professor & 0.153 & 0.044 & 11.983 & 1.16 (1.06 to 1.27$)$ & 0.001 \\
\hline Time of cannulation attempts by professor & 0.076 & 0.032 & 5.483 & 1.07 (1.01 to 1.15$)$ & 0.019 \\
\hline Prior cholecystectomy & 0.926 & 0.437 & 4.48 & $2.52(1.07$ to 5.94$)$ & 0.034 \\
\hline Pancreatic duct guidewire insertion & 2.186 & 0.464 & 22.19 & $4.38(1.44$ to 13.29$)$ & $<0.001$ \\
\hline
\end{tabular}


included 185 patients in the epinephrine group and 185 in the saline solution group, they found a decrease in the number of cases of PEP, $0 / 185$ cases in the epinephrine group and 4/185 cases in the saline solution group, however the $p$ value was 0.12 , its sample size was questioned. ${ }^{18}$ The other study was conducted by $\mathrm{Xu}$ et al in 2011, they included 461 patients in the epinephrine group and 480 in the saline solution group, they found a decrease in the number of cases of PEP, 9/461 cases in the epinephrine group and $31 / 480$ cases in the saline solution group, $\mathrm{p}$ value was $0.008 .{ }^{14}$ It should be noted that in both studies the ERCPs were only diagnostic, cannulation times were prolonged, there was not a standardised definition of PEP and rectal indomethacin was not used. When these results were included in the previously mentioned network meta-analysis, epinephrine sprayed into the papilla was effective in reducing the incidence of PEP (OR 0.25; 95\% CI 0.06 to 0.65 ; Number Needed to treat (NNT) 15). ${ }^{8}$

Our results are consistent with those of other studies that have explored the use of epinephrine in conjunction with rectal indomethacin. A randomised trial by Kamal et al in patients at high risk of PEP found an incidence of $6.4 \%(31 / 482)$ in the indomethacin-only group versus $6.7 \%(32 / 477)$ in the combination group $(p=0.87) .{ }^{16}$ Even though the PEP incidence was double that reported in the current study, likely because the study by Kamal et al was focussed on high-risk patients, the results point toward no added benefit of epinephrine in combination with indomethacin. While our study suggests that there is no added benefit of epinephrine, our findings do not suggest that it is detrimental to patients. This is in contrast to the findings of a multicentre double-blind trial performed by Luo and colleagues, in which 1158 patients were randomised to either indomethacin-only or indomethacin plus sprayed epinephrine groups, which found an increased incidence of PEP in the combination group $(5.3 \%$ vs $8.5 \%, \mathrm{p}=0.03) .{ }^{17}$ The authors concluded that sprayed epinephrine should not be used in combination with rectal indomethacin for the prevention of PEP because of the potential for increasing the incidence of PEP. We believe that this discordance could, at least in part, be due to the lower epinephrine concentration $(0.01 \%)$ used in the current study compared with that used by Kamal et al and Luo et al $(0.02 \%)$. It is possible that the vasoconstriction effect of epinephrine could reduce the bioavailability of indomethacin in the papilla area, precluding it from achieving a satisfactory result. Therefore, using a higher dose would probably accentuate this effect. Supporting this theory, Hatami and colleagues ${ }^{15}$ used a concentration equivalent to ours, achieving promising results without any detrimental effects. We consider that comparison of PEP incidence between patients who receive indomethacin alone versus epinephrine alone could be considered unethical at this time. To our knowledge, only the study of Hatami et al investigated the effect of epinephrine alone on PEP, in which 66 cases were randomised to the epinephrine-alone group, 68 individuals to the indomethacin group and 58 patients to the combination group. The overall incidence of PEP in this study was $3.6 \%(7 / 192)$, with six cases in the indomethacin group, one in the epinephrine group and no cases in the combination group; however, the small size of this study limits its conclusions. ${ }^{15}$

With our results, we cannot conclude that spraying epinephrine is harmful, but it does not appear to be useful, results that are accordant with the conclusion of a recently published systematic review and meta-analysis which included the studies of Hatami, Luo and Kamal et al. ${ }^{19}$ The reason behind this lack of effectiveness may be as Kamal and colleagues suggest, that epinephrine reduces the concentration of indomethacin, or, even worse, that epinephrine antagonises the effect of indomethacin. A third reason could be that epinephrine is not as good as indomethacin at preventing PEP, and that any benefit that it may confer is obscured by indomethacin. In order to sustain the last hypothesis, a non-inferiority trial would need to be conducted for epinephrine and indomethacin, although this will probably never happen due to ethical concerns. A fourth possible reason for the limited efficacy of epinephrine could be that, once it is sprayed, it has a short and limited time of action, which is insufficient to facilitate the flow of pancreatic juices in the mid-term.

One of the limitations of our study is that we had to stop enrolment earlier than planned, so our study may not have had enough power to detect superiority, as stipulated based on the sample size calculation, also the negative effects of the intervention could have been missed. However, based on our preliminary results, together with the findings of Kamal et al and Luo et al, we consider that it would have been unethical to continue with the study. Other important limitation is that patients were not randomised by level of risk for PEP. Another potential limitation is that we could not control the aggressiveness of hydration that patients received, which might have influenced the results, but is not a common practice in our hospital to give $3 \mathrm{~L}$ of intravenous fluid during ERCP. However, due to randomisation and masking, it is most probably the case that hydration aggressiveness ended up being equally distributed between the groups, also the high and low risk patients. A lot of our patients had a prior sphincterotomy because our institution is a high volume tertiary hospital and most of the cases evaluated are complicated and had previous ERCP, which could compromise the external validity and could affected some results, like PEP incidence. Our study also has several strengths. First, this study represents the first data from a Latin-American population. Second, the study was designed as a multicentre study with blinding of all significant physicians (doctors who performed the ERCP and those who evaluated the outcomes). Finally, we included patients with different levels of risk for PEP, making our results more applicable in clinical practice.

In conclusion, the addition of epinephrine sprayed on the papilla was no more effective than rectal indomethacin 
alone for the prevention of PEP, but it did not increase the risk of PEP or any other complication.

\section{Acknowledgements To CONACYT (CVU 429684).}

Contributors AFR-M, CM-V and FI. T-Á: conception and design; AFR-M, VJB-B and FI. T-Á: analysis and interpretation of the data; AFR-M and FI. T-Á: drafting of the article; AFR-M and FI. T-Á: critical revision of the article for important intellectual content; JJG-C, LFG-C, JR-G, LU-D, JAO-R, JFT-C, GV-A, DK-R, GG-F, MAR-L, FV-A and LZ-N: collected data; FIT-A, AFR-M, CM-V, JJG-C, LFG-C, JR-G, LU-D, JAO-R, JFT-C, GV-A, DK-R, GG-F, MAR-L, FV-A and LZ-N: final approval of the article.

\section{Funding National Council of Science and Technology (CONACYT) doctoral} scholarship.

Disclaimer The study sponsors had no role in the study design, collection, analysis, interpretation of data, writing of the report nor the decision to submit the manuscript.

Competing interests None declared.

Patient consent for publication Not required.

Ethics approval The study was approved by institutional review boards.

Provenance and peer review Not commissioned; externally peer reviewed.

Data availability statement Data are available upon reasonable request. Data will be available upon request to the correspondence author. Dr Félix Téllez-Avila: Instituto Nacional de Ciencias Médicas y NutriciónSalvador ZubiránVasco de Quiróga \#15, Sección XVI Tlalpan, Zip Code 14000, Mexico City, México. Email: felixtelleza@gmail.com.

Open access This is an open access article distributed in accordance with the Creative Commons Attribution Non Commercial (CC BY-NC 4.0) license, which permits others to distribute, remix, adapt, build upon this work non-commercially, and license their derivative works on different terms, provided the original work is properly cited, appropriate credit is given, any changes made indicated, and the use is non-commercial. See: http://creativecommons.org/licenses/by-nc/4.0/.

ORCID iD

Adriana Fabiola Romano-Munive http://orcid.org/0000-0002-3835-7465

\section{REFERENCES}

1 Rustagi T, Jamidar PA. Endoscopic retrograde cholangiopancreatography-related adverse events: general overview. Gastrointest Endosc Clin N Am 2015;25:97-106.

2 Rustagi T, Jamidar PA. Endoscopic retrograde cholangiopancreatography (ERCP)-related adverse events: postERCP pancreatitis. Gastrointest Endosc Clin N Am 2015;25:107-21.

$3 \mathrm{He}$ QB, Xu T, Wang J, et al. Risk factors for post-ERCP pancreatitis and hyperamylasemia: a retrospective single-center study. J Dig Dis 2015;16:471-8.
4 Ding X, Zhang F, Wang Y. Risk factors for post-ERCP pancreatitis: a systematic review and meta-analysis. Surgeon 2015;13:218-29.

5 Wang J, Shen Y, Zhong Z, et al. Risk factors for post-endoscopic retrograde cholangiopancreatography $(E R C P)$ pancreatitis and the effect of octreotide combined with nonsteroidal anti-inflammatory drugs on preventing its occurrence. Med Sci Monit 2018;24:8964-9.

6 Kubiliun NM, Adams MA, Akshintala VS, et al. Evaluation of pharmacologic prevention of pancreatitis after endoscopic retrograde cholangiopancreatography: a systematic review. Clin Gastroenterol Hepatol 2015;13:1231-9.

7 Wan J, Ren Y, Zhu Z, et al. How to select patients and timing for rectal indomethacin to prevent post-ERCP pancreatitis: a systematic review and meta-analysis. BMC Gastroenterol 2017;17:43.

8 Akshintala VS, Hutfless SM, Colantuoni E, et al. Systematic review with network meta-analysis: pharmacological prophylaxis against post-ERCP pancreatitis. Aliment Pharmacol Ther 2013;38:1325-37.

9 Andrade-Dávila VF, Chávez-Tostado M, Dávalos-Cobián C, et al. Rectal indomethacin versus placebo to reduce the incidence of pancreatitis after endoscopic retrograde cholangiopancreatography: results of a controlled clinical trial. BMC Gastroenterol 2015;15:85.

10 Elmunzer BJ, Waljee AK, Elta GH, et al. A meta-analysis of rectal NSAIDs in the prevention of post-ERCP pancreatitis. Gut 2008;57:1262-7.

11 Yang C, Zhao Y, Li W, et al. Rectal nonsteroidal anti-inflammatory drugs administration is effective for the prevention of post-ERCP pancreatitis: an updated meta-analysis of randomized controlled trials. Pancreatology 2017;17:681-8.

12 ASGE Standards of Practice Committee, Chandrasekhara V, Khashab MA, et al. Adverse events associated with ERCP. Gastrointest Endosc 2017;85:32-47.

13 Dumonceau J-M, Andriulli A, Elmunzer BJ, et al. Prophylaxis of post-ERCP pancreatitis: European Society of Gastrointestinal Endoscopy (ESGE) Guideline - updated June 2014. Endoscopy 2014:46:799-815.

$14 \mathrm{Xu} \mathrm{LH}$, Qian JB, Gu LG, et al. Prevention of post-endoscopic retrograde cholangiopancreatography pancreatitis by epinephrine sprayed on the papilla. J Gastroenterol Hepatol 2011;26:1139-44.

15 Hatami B, Kashfi SMH, Abbasinazari M, et al. Epinephrine in the prevention of post-endoscopic retrograde cholangiopancreatography pancreatitis: a preliminary study. Case Rep Gastroenterol 2018;12:125-36.

16 Kamal A, Akshintala VS, Talukdar R. A randomized trial of rectal indomethacin and papillary spray of epinephrine versus rectal indomethacin alone for the prevention of post-ERCP pancreatitis in high risk patients. Am J Gastroenterol 2019;114:339-47.

17 Luo H, Wang X, Zhang R, et al. Rectal indomethacin and spraying of duodenal papilla with epinephrine increases risk of pancreatitis following endoscopic retrograde cholangiopancreatography. Clin Gastroenterol Hepatol 2019;17:1597-606.

18 Matsushita M, Takakuwa H, Shimeno N, et al. Epinephrine sprayed on the papilla for prevention of post-ERCP pancreatitis. $J$ Gastroenterol 2009;44:71-5

19 Aziz M, Ghanim M, Sheikh T, et al. Rectal indomethacin with topica epinephrine versus indomethacin alone for preventing Post-ERCP pancreatitis - A systematic review and meta-analysis. Pancreatology 2020;20:356-61. 